\title{
Sildenafil as First Line Treatment in Persistent Pulmonary Hypertension of the Newborn: Near Future Perspective
}

\author{
Sinan Uslu ${ }^{\mathrm{a}, \mathrm{b}}$, Ali Bulbul ${ }^{\mathrm{a}}$, Serdar Comert ${ }^{\mathrm{a}}$
}

\section{To the Editor:}

We read a recent article with great interest, about "Magnesium Sulphate Versus Sildenafil in the Treatment of Persistent Pulmonary Hypertension of the Newborn" which has been reported by of Shaltout F. et al.[1]. Because of the high morbidity and mortality and the difficulty of the treatment, persistent pulmonary hypertension ( $\mathrm{PPH}$ ) remains as an important disease of the newborns in developing countries [2]. In fact, alternative selective vasodilator treatments (such as sildenafil and magnesium sulphate $\left(\mathrm{MgSO}_{4}\right)$ ) for $\mathrm{PPH}$ with acceptable side effects seem to be very valuable for the neonatologists. Therefore the results of this clinical trial are extremely useful for clinicians.

In our study sildenafil was also found to be effective in the treatment of PPH with adequate clinical response [3]. But we want to highlight some differences. We think that vasodilator therapy is a more appropriate management to being a dynamic approach for PPH. For this reason, if the clinic condition and oxygenation index do not improve sufficiently, the $\mathrm{MgSO}_{4}$ infusion rate may increase $(10 \mathrm{mg} / \mathrm{kg} / \mathrm{h}$ to maximum $100 \mathrm{mg} / \mathrm{kg} / \mathrm{h}$ ) and the sildenafil dose can be doubled (until reaching a maximum of $2 \mathrm{mg} / \mathrm{kg}$ ) every 6 hours.

It's reported that systemic blood pressure may be found to be decreased (resulting from both heart failure and persistent hypoxemia) in newborns with PPH, and in addition that during selective vasodilator treatment hypotension may develop also [4]. In our study since we aimed to keep the systemic blood pressure of the patients at about $50^{\text {th }}$ percen-

Manuscript accepted for publication June 11, 2012

${ }^{a}$ Specialist in Neonatology, Department of Pediatrics, Division of Neonatology, Sisli Etfal Children Hospital, Istanbul, Turkey

${ }^{b}$ Corresponding author: Sinan Uslu, Darusafaka mah, Acelya sok, Yonca sit, 1B blok D:9 34460 Istinye, Istanbul, Turkey.

Email: sinanuslumd@hotmail.com

doi:10.4021/ijcp30w tile, $82.3 \%$ of the patients in $\mathrm{MgSO}_{4}$ group and $45.2 \%$ of the patients in sildenafil group was found to receive inotropic support [3].

Sildenafil may not be as effective in certain causes of $\mathrm{PPH}$ such as gastrointestinal bleeding, gastric intolerance and sepsis (where over production of nitric oxide leading to systemic vasodilation may the major mechanism) [5]. Sildenafil can cause significant systemic hypotension, particularly in patients who have unusually high levels of circulating cGMP as seen in sepsis [6]. Therefore we suggest that in studies evaluating effects of sildenafil for PPH, patients with sepsis should not be included. Gastric intolerance and/or bleeding may affect the bioavailability of oral sildenafil negatively. The issues that whether patients with gastric intolerance and/ or bleeding were included in the study or not and which of the patients were excluded from the study were not clearly outlined. The addition of a consort diagram would make the method easier to understand.

Pharmacokinetics of oral sildenafil in neonates are highly variable. Therefore demonstration of bioavailability of oral sildenafil with serum sildenafil levels would strengthen the comments about the efficacy of sildenafil. On the other hand intravenous sildenafil may be select if it is avaible in region [6].

Although the effectiveness of sildenafil in PPH had been documented in controlled and uncontrolled studies, the paucity of literature data about the long-term follow up of these patients and the cost-effectiveness of the drug suggest that future studies should target these important issues.

Regarding the studies showing the effectiveness of sildenafil for treatment of $\mathrm{PPH}$ in newborns, with features like acceptable side effects, low cost and ease of use, we strongly think that sildenafil would replace first choice treatments such as iNO and HFOV and would probably stand as a first line treatment agent in the near future.

\section{Conflict of Interest}

The authors have indicated that they have no financial relationships relevant to this article to disclose and no conflict of interest. 


\section{References}

1. Shaltout F, Hegazy R, Aboulghar H, Motelb LA. Magnesium sulphate versus sildenafil in the treatment of persistent pulmonary hypertension of the newborn. Int $\mathbf{J}$ Clin Pediatr. 2012;1(1):19-24.

2. Walsh MC, Stork EK. Persistent pulmonary hypertension of the newborn. Rational therapy based on pathophysiology. Clin Perinatol. 2001;28(3):609-627, vii.

3. Uslu S, Kumtepe S, Bulbul A, Comert S, Bolat F, Nuhoglu A. A comparison of magnesium sulphate and sildenafil in the treatment of the newborns with persistent pulmonary hypertension: a randomized controlled trial.
J Trop Pediatr. 2011;57(4):245-250.

4. Mukherjee A, Dombi T, Wittke B, Lalonde R. Population pharmacokinetics of sildenafil in term neonates: evidence of rapid maturation of metabolic clearance in the early postnatal period. Clin Pharmacol Ther. 2009;85(1):56-63.

5. Shah PS, Ohlsson A. Sildenafil for pulmonary hypertension in neonates. Cochrane Database Syst Rev. 2011;8:CD005494.

6. Stocker C, Penny DJ, Brizard CP, Cochrane AD, Soto $\mathrm{R}$, Shekerdemian LS. Intravenous sildenafil and inhaled nitric oxide: a randomised trial in infants after cardiac surgery. Intensive Care Med. 2003;29(11):1996-2003. 